\title{
Giant Intrathoracic Lipoma
}

Mohammad S. Siddiqi, "Adil H. Al Kindi, Malyar Al Marhoon, AbdulMageed Salem

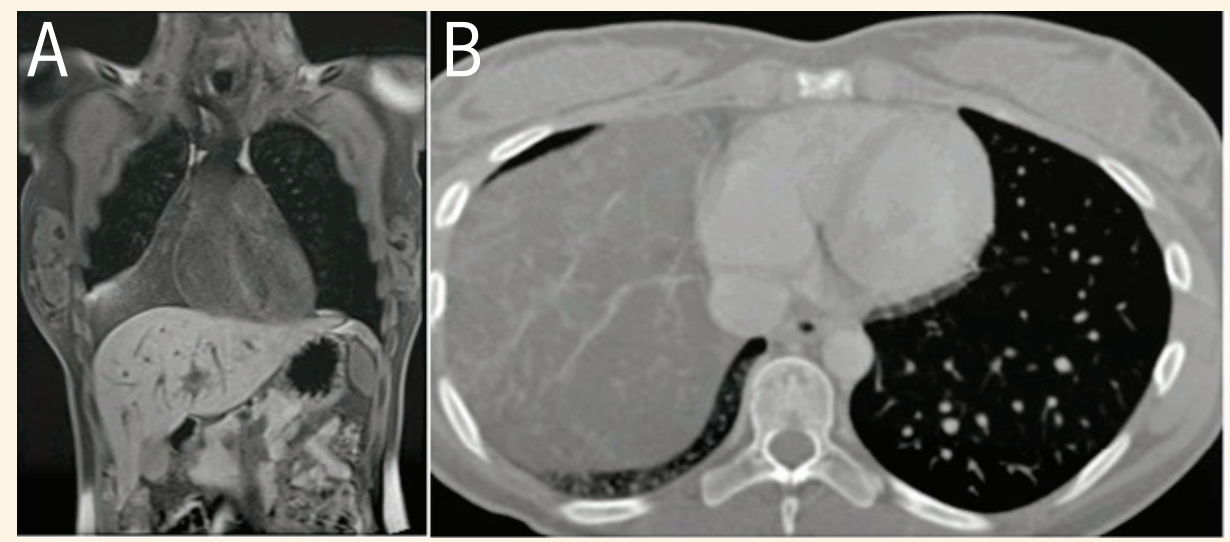

Figure 1: Computed tomography scans showing (A) coronal and (B) axial views of a huge and well-defined intrathoracic mass in a 27-year-old female.

$\mathrm{M}$ OST LIPOMAS ARE SLOW-GROWING SOFT tissue tumours that rarely reach $2 \mathrm{~cm}$ in size. Those reaching more than five $\mathrm{cm}$ are called giant lipomas and are an exceedingly rare entity. ${ }^{1}$ The following is a description of a case of a large intrathoracic lipoma compressing the right lung managed by complete excision through a median sternotomy.

A 27-year-old female patient presented to the obstetrics department of a tertiary care hospital in Muscat, Oman, in 2019 with abdominal pain. An abdominal X-ray revealed a space-occupying lesion on the right side of the chest above the diaphragm as an incidental finding. The patient was referred to the cardiothoracic surgery department for assessment and management. A computed tomography scan showed an anterior mediastinal mass extending into the right thoracic cavity [Figure 1]. Magnetic resonance imaging showed a large fat density lesion in the right hemithorax that appeared inseparable from the thymus [Figure 2].

The mass was exposed through median sternotomy given that the tumour was arising from the anterior mediastinum. Following sternotomy, the large mass was seen arising from the thymic area and extending into the right pleural cavity above the diaphragm and compressing the right lower lobe of the lung. The tumour grossly appeared as a light-yellow coloured, soft, encapsulated mass with a smooth surface [Figure 3]. It was attached by its pedicle to the thymus, adjacent to the right phrenic nerve. Removed en-bloc along with the thymus gland, the tumour weighed $2.32 \mathrm{~kg}$ and measured $38 \times 26 \times 15$ $\mathrm{cm}$ in dimensions. A histopathology of the specimen confirmed the diagnosis of benign thymolipoma [Figure 4]. The post-operative period was uneventful and the patient was discharged after four days.

Consent was obtained from the patient for the publication of the case and associated images.

\section{Comment}

Lipomas are benign mesenchymal tumors. ${ }^{2}$ Although they are predominantly found originating in the subcutaneous tissues of the body, they can rarely originate in the intrathoracic cavity in the mediastinum or intrapulmonary areas. Intrathoracic lipoma has two variants: an hourglass or dumbbell-shaped tumour that originates in the subcutaneous tissue and enters through the intercostal space or thoracic inlet into the thoracic cavity while the other is purely intrathoracic. ${ }^{3}$ The current case belongs to the second category as the tumour was situated entirely within the chest cavity. Mediastinal lipomas commonly originate within the anterior mediastinum and constitute $1.6-2.3 \%$ of all primary mediastinal tumors. ${ }^{2}$ Thymolipoma is a 


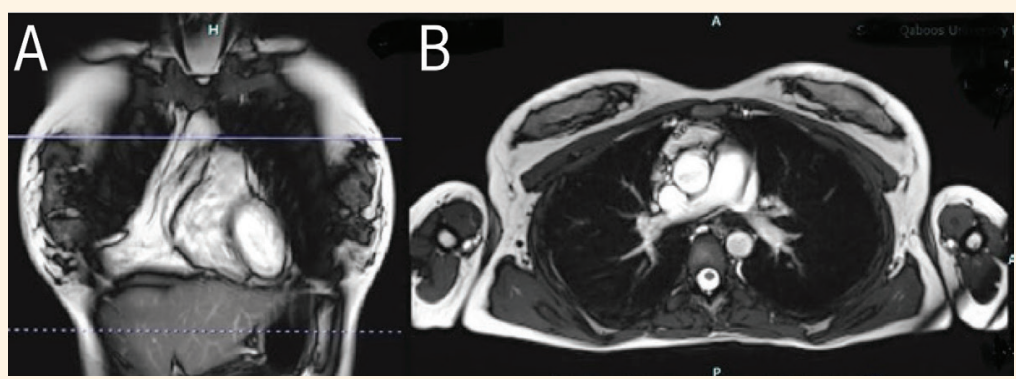

Figure 2: Magnetic resonance imaging scan showing (A) coronal and (B) axial views of a large fat density lesion at the thymic level appearing inseparable from the thymus in the right hemithorax of a 27 -year-old female.

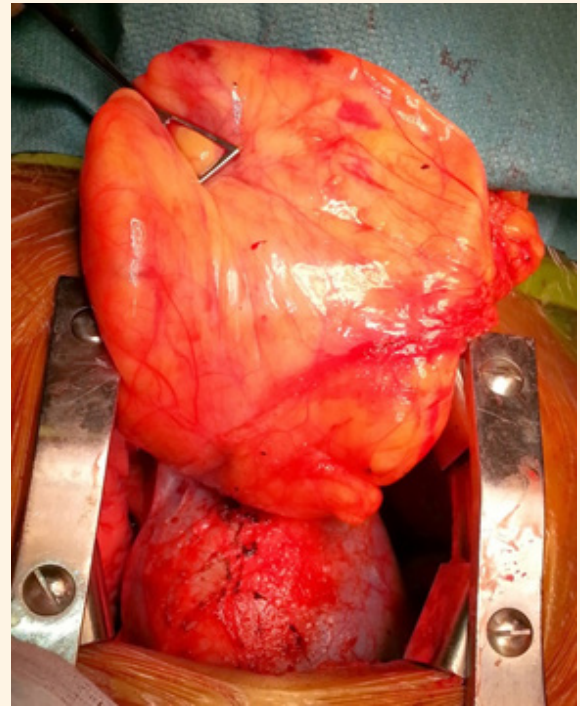

Figure 3: Photograph of a mediastinal mass with an attachment to the thymus in the anterior mediastinum following dissection in a 27-year-old female.

benign variant of this type and accounts for $2-9 \%$ of all thymic neoplasms. ${ }^{4}$ Microscopic examination typically shows exuberant lymphoid nodular hyperplasia with thymomatous differentiation, as is seen in the current case. Liposarcoma was reported to constitute $9 \%$ of all anterior mediastinal malignancies in a case series by Burt et al. ${ }^{5}$

These lipomas are slow-growing and patients generally remain asymptomatic until the lipoma grows to a large size and starts producing compressive symptoms. The symptoms of dyspnoea and dysphagia are due to pressure effects on the trachea and oesophagus, respectively. ${ }^{5}$ These lipomas are found incidentally during radiological examination in the majority of cases. Computed tomography provides a confirmed diagnosis when it shows a homogeneous fatty attenuation ( -50 to -150 Hounsfield units) forming an obtuse angle with the chest wall and compressing the adjacent structures. ${ }^{6}$ The density may vary because lipomas often contain fibrous elements. ${ }^{6}$

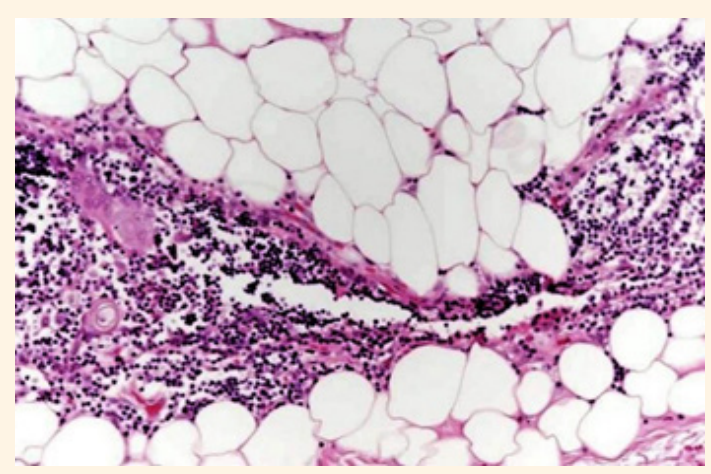

Figure 4: Haematoxylin and eosin stain at $\times 400$ magnification of a mediastinal mass showing islands of unremarkable thymic tissue within a mature adipose tissue of a 27-year-old female patient.

In the current case, the mass appeared to be benign as it was well-encapsulated with well-circumscribed margins. Malignant lesions tend to invade the surrounding structures and are symptomatic. On imaging, they produce non-homogenous enhancing density with variable fat and soft tissue density, along with an invasion of surrounding structures. ${ }^{7}$

The current recommendations include complete excision whenever feasible because it is difficult to differentiate a lipoma from liposarcoma preoperatively and, albeit low risk, they may undergo malignant transformation. The approach depends on the site and the size of the mass. Median sternotomy, or thoracotomy, appears to be the best procedure for total resection of these large masses. Video-assisted thoracoscopy can be used in small, uncomplicated and adhesion-free tumours. The local recurrence of these tumours is uncommon and has been reported to be less than $5 \%{ }^{8}$ The overall prognosis after complete resection is excellent.

\section{AUTHORS' CONTRIBUTION}

MSS drafted the manuscript and AAK edited the manuscript. MAM performed the literature review. AMS formatted the images. All authors approved the final version of the manuscript. 


\section{References}

1. Cribb GL, Cool WP, Ford DI, Mangham DC. Giant lipomatous tumours of the hand and forearm. J Hand Surg Br 2005; 30:509-12. https://doi.org/10.1016/j.jhsb.2005.05.002.

2. Politis J, Funahashi A, Gehlsen JA, DeCock D, Stengel BF, Choi $\mathrm{H}$ : Intrathoracic lipomas: Report of three cases and review of the literature with emphasis on endobronchial lipoma. J Thorac Cardiovasc Surg 1979, 77:550-6. https://doi.org/10.1016/S002 2-5223(19)38260-1.

3. Keeley JL, Vana AJ: Collective reviews: Lipomas of the mediastinum: 1940- 1955. Int Abstr Surg 1955; 103:313-22.

4. Gaerte SC, Meyer CA, Winer-Muram HT, Traver RD, Conces DJ: Fat-containing lesions of the chest. Radiographics 2002; 22:61-78. https://doi.org/10.1148/radiographics.22.suppl_1.g02oc08s61.
5. Burt M, Ihde JK, Hajdu SI, Smith JW, Bains MS, Downey R, et al. Primary sarcomas of the mediastinum: Results of therapy. J Thorac Cardiovasc Surg 1998; 115:671-80. https://doi. org/10.1016/S0022-5223(98)70333-2.

6. Buxton RC, Tan CS, Khane NM, Cuasay NS, Shor MJ, Spigos DG. Atypical transmural thoracic lipoma: CT diagnosis. J Comput Assist Tomogr 1988, 12:196-8. https://doi. org/10.1097/00004728-198803000-00002.

7. Shahrzad M, Le TSM, Silva M, Bankier AA, Eisenberg RL. Anterior Mediastinal Masses. AJR Am J Roentgenol 2014; 203:W128-38. https://doi.org/10.2214/AJR.13.11998.

8. Sakurai H, Kaji M, Yamazaki K, Suemasu K: Intrathoracic lipomas: Their Clinicopathological Behaviors Are Not As Straightforward as Expected. Ann Thorac Surg 2008; 86:261-5. https://doi.org/10.1016/j.athoracsur.2008.03.052. 